reported by China's mainstream media and more than 2 million people viewed the news online.

With the support of several conservation projects, research has examined the threats to these two species, and conservation measures have been implemented. The wild populations of both species are protected by national natural reserves and micro-conservation sites established by local government departments. Thousands of seedlings have been propagated, some of which have been used for reinforcement and reintroduction in natural and seminatural sites within the species' known range, and others are being cultivated in various botanical gardens.

LIDAN TAO (@ orcid.org/0000-0002-1396-0524,wbsun@mail. kib.ac.cn) and WEIBANG SUN Yunnan Key Laboratory for Integrative Conservation of Plant Species with Extremely Small Populations, Kunming Institute of Botany, Chinese Academy of Sciences, Kunming, Yunnan, China. ZHIFA CHEN Kunming Botanical Garden, Kunming Institute of Botany, Chinese Academy of Sciences, Kunming, Yunnan, China

This is an Open Access article, distributed under the terms of the Creative Commons Attribution licence CC BY NC 4.0.

\section{An integrative approach for fungal conservation in southern Brazil}

Tropical cloud forests are characterized by occurring at mid to high elevations, and having high relative humidity, frequent presence of clouds, high biodiversity and a high per cent of endemic species. As a result of the intrinsic characteristics of this ecosystem, many of its species, in particular endemics, are highly threatened.

Since 2011, to mitigate the perilous combination of a threatened habitat and lack of knowledge about the fungi of the cloud forests of southern Brazil, the MIND.Funga initiative (mindfunga.ufsc.br) has been carrying out taxonomic and biodiversity studies and Red List assessments, as well as promoting citizen science and environmental education. More than 2,000 specimens of macrofungi, representing over 700 species, have been studied, new species described and an environmental education book for children published (mindfunga. ufsc.br/nossos-projetos/sbpc-vai-a-escola/?lang=en). Up to August 2021 the book had been downloaded c. 3,200 times.

On 25 March 2021, conservation assessments of three additional species were published on the IUCN Red List: Skeletocutis roseola and Stropharia venusta are categorized as Vulnerable and Wrightoporia araucariae as Critically Endangered. These are among the first Brazilian fungal species to be included on the Red List. So far, 46 species occurring in Brazil have been assessed.

Since March 2021, to improve knowledge of fungi in Brazil and to provide a new tool for conservation, we have been developing a citizen science programme. As part of this, a mobile application has been developed. We have so far trained 30

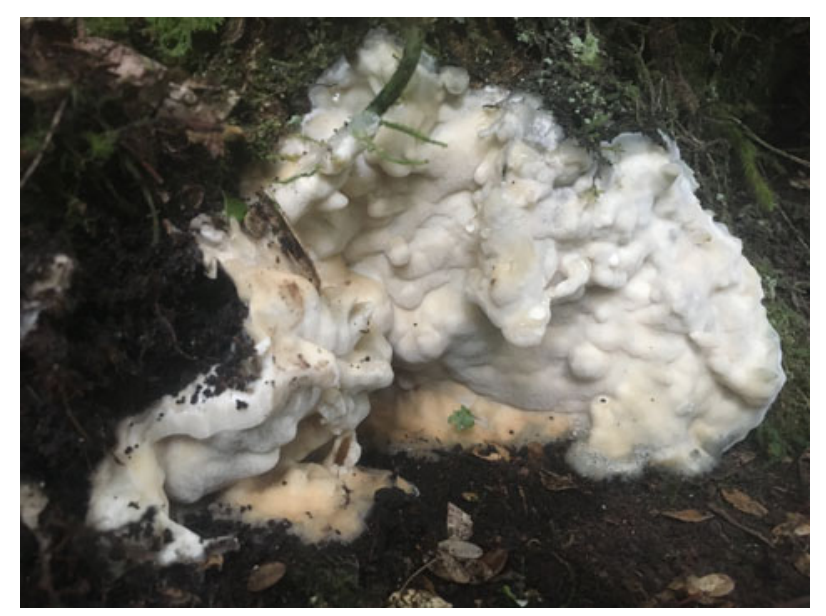

The Vulnerable Laetiporus squalidus (iucnredlist.org/species/ 187000831/187004590), a rare brown-rot polypore known only from the cloud forests and other montane ecosystems of the Serra do Mar. Photo: Cauê Azevedo Tomas de Oliveira.

collaborating citizens in using the application, and they have already registered 802 images of fungi, representing 206 specimens from cloud forests and adjacent areas, amongst which we have so far identified 74 species. The species most commonly found is Schizophyllum commune and none of the species known to be threatened have so far been recorded in this way. As a research group we believe that contributing to improved knowledge of the fungi of cloud forests in association with nonscientists, including children, will improve both fungal conservation and the conservation of the cloud forests of southern Brazil.

These MIND.Funga initiatives are supported by Fundação de Amparo à Pesquisa e Inovação de Santa Catarina (PRONEM2020TR733) and Conselho Nacional de Desenvolvimento Científico e Tecnológico (PQ311158/2018-8).

Diogo H. Costa-REZENDE (10 orcid.org/0000-0002-7381-6954) Laboratório de Pesquisa em Microbiologia, Departamento de Biologia, Universidade Estadual de Feira de Santana, Feira de Santana, Bahia, Brazil. Thiago Kossmann (잉 orcid.org/00000003-2858-7838), MAHATMÃ TitTON (10 orcid.org/0000-00017139-5116) and ELISANDRO RICARDO DRECHSLER-SANTOS* (ㅇ orcid. org/0000-0002-3702-8715,drechslersantos@yahoo.com.br) Laboratório de Micologia, Departamento de Botânica, Universidade Federal de Santa Catarina, Campus Universitário Trindade, Florianópolis, Santa Catarina, Brazil

${ }^{*}$ Also at: IUCN Species Survival Commission Mushroom, Bracket, and Puffball Specialist Group

This is an Open Access article, distributed under the terms of the Creative Commons Attribution licence CC BY 4.0.

\section{New toolkit to support teachers to teach about Philippine biodiversity}

A group of biodiversity researchers and conservation practitioners in the Philippines has teamed up with the country's 
Department of Education to produce a biodiversity toolkit that will be made available to teachers nationwide. This endeavour is one of the largest efforts to incorporate biodiversity and conservation in Philippine schools.

Across its more than 7,600 islands, the biodiversity of the Philippines is both rich and highly threatened, and the country is recognized as a biodiversity hotspot. The general low awareness about this biodiversity, however, compounds the threats to species and ecosystems, resulting in misguided policies and practices for natural resource management. Schools are not well equipped to teach about biodiversity, and teachers, especially non-biology subject teachers, have limited resources for this purpose.

To support teachers across the school curriculum, a new resource about the biodiversity of the Philippines was made publicly available in December 2021. Samot-Saring Buhay: A Toolkit on Philippine Biodiversity for Filipino primary and secondary school teachers provides educators with knowledge and resources to incorporate biodiversity into classroom lessons and discussions.

The toolkit provides an overview of biodiversity, the ecosystem services it provides, and the threats to species and ecosystems, using examples from the Philippines. It relates the relevance of biodiversity to Filipino culture, livelihoods, social welfare, disaster risk management, history and current affairs, to help educators explain and integrate the topic across subjects, from science to social studies and the arts. The toolkit draws on examples of conservation work from across the Philippine archipelago, featuring 150 profiles of Philippine species, 50 infographics, and a directory of organizations working on Philippine biodiversity research and conservation.

Filipino biodiversity researchers and conservation practitioners developed the toolkit in a partnership between the Biodiversity Conservation Society of the Philippines and the Department of Education. The toolkit is freely accessible to the more than 800,000 public and 300,000 private school teachers in primary and secondary schools in the country. Anyone interested in learning or teaching about the biodiversity of the Philippines is encouraged to download and use this resource, freely available from the Department of Education (deped.gov.ph/climate-change-education) and the Biodiversity Conservation Society of the Philippines (biodiversity.ph).

Cynthia Adeline A. Layusa (ㅇ orcid.org/0000-0002-6446-0212, cynthia.layusa@gmail.com), MICHELLE V. ENCOMIENDA, Gisselle Millete M. Belardo, Frances Mae B. Tenorio, Prime F. PRemne and Rina B. De Alban Biodiversity Conservation Society of the Philippines, Quezon City, Philippines.

$J_{A Y}$ S. FIDELINO University of the Philippines Diliman-Institute of Biology, Quezon City, Philippines. CZarina C. Panopio University of the Philippines Open University, Laguna, Philippines. AlmaLYN C. MAdRID, LARA JeAn L. Salaysay and RONILDA R. Co Department of Education, Pasig City, Philippines

This is an Open Access article, distributed under the terms of the Creative Commons Attribution licence CC BY NC SA 4.0.

\section{Supporting rangers: a 5-year Action Plan from the Universal Ranger Support Alliance}

The 9th World Ranger Congress in 2019 and the resulting Chitwan Declaration, drafted by more than 550 rangers, outlined the challenges and needs of the ranger sector to achieve better conservation outcomes in protected areas. Based on this call to action, the Universal Ranger Support Alliance, a global coalition of conservation and ranger organizations, was established in 2020. In July 2021, guided by the vision of 'a network of well-supported, professionally competent, mandated, motivated, responsible and representative rangers working effectively as custodians of biodiversity and the life systems upon which we all depend', the Alliance launched a 5-year Action Plan.

Rangers play critical roles in the effective management of protected areas, conserving natural and cultural heritage and safeguarding the rights of all who depend on nature. They need to be recognized and resourced, empowered and supported if protected areas are to contribute meaningfully to the post-2020 biodiversity framework and the Sustainable Development Goals. The key themes of the 2019 Chitwan Declaration subsequently informed the five strategic objectives of the Action Plan: (1) Advocacy and Representation Rangers need to be formally recognized as a profession and well represented by ranger associations, (2) Ranger Capacity Rangers and their employers need to have the competencies and capacity (both in terms of adequate personnel and resources) to perform their roles effectively, (3) Employment and Welfare Rangers globally need to operate under minimum acceptable standards of employment and welfare, (4) Equity and Equality Rangers have the right to equal opportunities in a working environment where they are not discriminated against, regardless of race, religion, gender, sexual orientation, culture or background, and (5) Community Relations, Conduct and Accountability Rangers must build trusting relationships with local communities, behaving in a responsible and accountable manner at all times.

The Plan lists multiple actions and outputs for each objective, some of which, such as the Global Code of Conduct (internationalrangers.org/toolkit/ranger-code-of-conduct-2), have already been developed and/or implemented. The Universal Ranger Support Alliance recognizes the value of collaboration and the opportunity created when leveraging the strengths of multiple partners, and therefore invites like-minded members, partners and supporters to join the Alliance and deliver the Action Plan to support rangers. For more details, visit ursa4rangers.org.

OLGA BIEGUS (이이.org/0000-0001-8507-8250, obiegus@ ursa4rangers.org) Universal Ranger Support Alliance, Re:Wild, Austin, USA

This is an Open Access article, distributed under the terms of the Creative Commons Attribution licence CC BY 4.0. 